\title{
Moho Interface Modeling Beneath the Himalayas, Tibet and Central Siberia Using GOCO02S and DTM2006.0
}

\author{
Robert Tenzer ${ }^{1, *}$, Mohammad Bagherbandi ${ }^{2,3}$, Cheinway Hwang ${ }^{4}$, and Emmy Tsui-Yu Chang ${ }^{5}$ \\ ${ }^{1}$ School of Geodesy and Geomatics, Wuhan University, Wuhan, China \\ ${ }^{2}$ Division of Geodesy and Geoinformatics, Royal Institute of Technology (KTH), Stockholm, Sweden \\ ${ }^{3}$ Department of Industrial Development, IT and Land Management University of Gävle, Gävle, Sweden \\ ${ }^{4}$ Department of Civil Engineering, National Chiao Tung University, Hsinchu, Taiwan \\ ${ }^{5}$ Division of Marine Geology and Geophysics, Institute of Oceanography, National Taiwan University, Taipei, Taiwan
}

Received 5 March 2012, accepted 1 November 2012

\begin{abstract}
We apply a newly developed method to estimate the Moho depths and density contrast beneath the Himalayas, Tibet and Central Siberia. This method utilizes the combined least-squares approach based on solving the inverse problem of isostasy and using the constraining information from the seismic global crustal model (CRUST2.0). The gravimetric forward modeling is applied to compute the isostatic gravity anomalies using the global geopotential model (GOCO02S) and the global topographic/bathymetric model (DTM2006.0). The estimated Moho depths vary between $60-70 \mathrm{~km}$ beneath most of the Himalayas and Tibet and reach the maxima of $\sim 79 \mathrm{~km}$. The Moho depth under Central Siberia is typically $50-60 \mathrm{~km}$. The Moho density contrast computed relative to the CRUST2.0 lower crustal densities has the maxima of $\sim 300 \mathrm{~kg} \mathrm{~m}^{-3}$ under Central Tibet. It substantially decreases to $150-250 \mathrm{~kg} \mathrm{~m}^{-3}$ under Himalayas and north Tibet. The estimated Moho density contrast under central Siberia is within $100-200 \mathrm{~kg} \mathrm{~m}^{-3}$.
\end{abstract}

Key words: Crust, Gravity, Himalaya, Isostasy, Moho interface, Tibet plateau

Citation: Tenzer, R., M. Bagherbandi, C. Hwang, and E. T.-Y. Chang, 2013: Moho interface modeling beneath the Himalayas, Tibet and Central Siberia using GOCO02S and DTM2006.0. Terr. Atmos. Ocean. Sci., 24, 581-590, doi: 10.3319/TAO.2012.11.01.02(TibXS)

\section{INTRODUCTION}

Starting from the 1980s systematic studies of the lithospheric structure in the Himalayas and Tibet were carried out in the frame of the GGT, IRIS/1991-92PASSCAL and INDEPTH/GEDEPTH geophysical projects. Zhao et al. (1993) analyzed the seismic reflection data collected at the profile INDEPTH-I across the Himalayas. He estimated that the largest Moho depths reach $\sim 75 \mathrm{~km}$. This value is consistent with the values of $75-78 \mathrm{~km}$ along the INDEPTHII seismic reflection profile obtained by Teng et al. (1983), Wu et al. (1995), and Gao et al. (2005). Zeng et al. (1994) reported the Moho depths to $80-84 \mathrm{~km}$ to the south of the Bangong-Nujiang suture. More recently, Schulte-Pelkum et al. (2005) reported the Moho depths to $\sim 75 \mathrm{~km}$ beneath the Tethyan Himalayas. Kind et al. (2002) estimated based on processing the seismic data collected along the profile

\footnotetext{
* Corresponding author

E-mail:rtenzer@sgg.whu.edu.cn
}

INDEPTH-III that the Tibetan crust varies in thickness from a maximum of about $78 \pm 3 \mathrm{~km}$ to a minimum of about $65 \pm$ $3 \mathrm{~km}$; with the maximum thickness within the Lhasa terrane. Allègre et al. (1984), Wu et al. (1991), Nelson et al. (1996), and Kind et al. (1996) concluded that a typical crustal thickness under the Tibet plateau is $70-80 \mathrm{~km}$ with a probably partially molten crust beneath the depth of $20-30 \mathrm{~km}$, characterized by high conductivity and a seismic low-velocity zone. Hirn et al. (1984) estimated that the average depth beneath the Lhasa terrane is $\sim 55 \mathrm{~km}$, while the average value of $70 \mathrm{~km}$ was suggested by Wu et al. (1995). Zhang et al. (2001) estimated the Moho depths in northern Tibet to be at least $80 \mathrm{~km}$. Teleseismic receiver function analysis of seismograms recorded on a $\sim 700 \mathrm{~km}$ long profile of 17 broadband seismographs traversing the north-west Himalayas conducted by Rai et al. (2006) revealed a progressive northward Moho deepening from $\sim 40 \mathrm{~km}$ beneath Delhi south of the Himalayan fore deep to $\sim 75 \mathrm{~km}$ beneath Taksha at the Karakoram fault. An earlier study by Wittlinger et al. 
(2004) to the north of the Karakoram fault showed that the Moho continues to deepen to $\sim 90 \mathrm{~km}$ beneath western Tibet before decreasing substantially to $50-60 \mathrm{~km}$ at the Altyn Tagh fault. Bagherbandi (2012) applied and compared three different isostatic methods (based on solving the VeningMeinesz Moritz models and using Parker-Oldenburg's algorithm) to estimate the Moho depths beneath Tibet and Himalayas. According to his results the maximum Moho depths reach $67-72 \mathrm{~km}$ depending on the method applied. The regional isostatic studies were conducted also by Lyon-Caen and Molnar (1983, 1984), Caporali (1995, 1998, 2000), Braitenberg et al. (2000a, b), Watts (2001), and others. The studies of the Siberian and Baikal crustal structures can be found, for instance, in Pavlenkova (1996), Zorin et al. (2002), and Pavlenkova and Pavlenkova (2006).

In this study we apply a novel approach developed by Sjöberg (2009) and Sjöberg and Bagherbandi (2011) to estimate the Moho depths and density contrast. The numerical realization at the study area of the Himalayas, Tibet and Central Siberia is done using recently released global models of the Earth gravity, topography, bathymetry and crustal thickness. The gravimetric results are compared with the seismic model from the global crustal model CRUST2.0 as well as more detailed regional studies.

\section{METHODOLOGY}

Sjöberg and Bagherbandi (2011) developed and applied the least-squares method for a simultaneous estimation of the Moho depths and density contrast based on solving the inverse problem of isostasy and using the constraining information from seismic data. They formulated the linearized observation equations for the product of $T \Delta \rho$ and $\Delta \rho$ for as follows

$$
\begin{aligned}
T(\Omega) \Delta \rho(\Omega)= & \sum_{n=0}^{N_{\max }} \sum_{m=-n}^{n}\left[\frac{2 n+1}{4 \pi G(n+1)} \Delta g_{n, m}^{i}-\frac{n+2}{2}\left(\Delta \rho T^{2}\right)_{n, m}\right] \\
& \cdot Y_{n, m}(\Omega)
\end{aligned}
$$

and

$$
\begin{aligned}
\Delta \rho(\Omega)= & \frac{\Delta g^{i}(r, \Omega)}{2 \pi G T(\Omega)}-\frac{1}{4 \pi T(\Omega)} \\
& \cdot \sum_{n=0}^{N_{\max }} \sum_{m=-n}^{n}\left[\frac{1}{n+1}-\frac{T_{0} / R}{2 /(n+2)-T_{0} / R}\right] \Delta g_{n, m}^{i} Y_{n, m}(\Omega)
\end{aligned}
$$

where $T$ is the Moho depth; $\Delta \rho$ is the Moho density contrast; $G=6.674 \times 10^{-11} \mathrm{~m}^{3} \mathrm{~kg}^{-1} \mathrm{~s}^{-2}$ is the Newton gravitational constant; $R=6371 \times 10^{3} \mathrm{~m}$ is the Earth mean radius; $\Delta g^{i}$ is the isostatic gravity anomaly; $Y_{n, m}$ is the surface spherical harmonic function of degree $n$ and order $m$; and $N_{\max }$ is the upper summation index of spherical harmonics. The 3-D position is defined in the system of spherical coordinates $(r, \Omega)$; where $r$ is the spherical radius and $\Omega=(\phi, \lambda)$ denotes the spherical direction with the spherical latitude $\phi$ and longitude $\lambda$.

As seen from Eq. (2), if $T$ is known, the crust-mantle density contrast $\Delta \rho$ can be estimated from the spectrum of $\Delta g_{n, m}^{i}$. The isostatic gravity anomalies in Eqs. (1) and (2) are computed in the spectral domain using the following expression (Sjöberg 2009)

$\Delta g_{n, m}^{i}=\frac{1}{4 \pi} \begin{cases}2 \pi G\left(\bar{\rho}^{c} H\right)_{0,0}-\tilde{g}_{0}^{c} & \text { if } n=0 \\ 2 \pi G\left(\bar{\rho}^{c} H\right)_{n, m}-\Delta g_{n, m} & \text { otherwise }\end{cases}$

where $\Delta g_{n, m}$ and $\Delta g_{n, m}^{i}$ are the spherical harmonics of the gravity anomalies and isostatic gravity anomalies respectively; $2 \pi G\left(\bar{\rho}^{c} H\right)_{n, m}$ is the spectral Bouguer gravity reduction term which is defined by means of the coefficients of global topographic/bathymetric (density) spherical functions $\left(\bar{\rho}^{c} H\right)_{n, m}$. The density distribution function $\bar{\rho}^{c}$ equals $\bar{\rho}^{c}=\rho^{c}$ on land, where $\rho^{c}$ is the reference crustal density. The ocean density contrast is defined as $\bar{\rho}^{c}=\rho^{c}-\rho^{w}$; where $\rho^{w}$ is the mean seawater density. The nominal compensation attraction (of zero-degree) $\tilde{g}_{0}^{c}$ stipulated at the sphere of radius $R$ is computed as (cf. Sjöberg 2009)

$\tilde{g}_{0}^{c}=\left.g_{0}^{c}(r, \Omega)\right|_{r=R} \approx-4 \pi G \Delta \rho_{0} T_{0}$

where $T_{0}$ and $\Delta \rho_{0}$ are the adopted nominal mean values of the Moho depth and density contrast respectively.

The least-squares analysis combines the estimated product of $T$ and $\Delta \rho$ with the a priori values $t$ and $\kappa$ of these parameters in order to obtain the improved estimates of $T$ and $\Delta \rho$. The system of observation equations, formulated for both parameters, is written in the following vectormatrix form

$\mathbf{A x}=\mathbf{l}-\boldsymbol{\varepsilon}$

where $\boldsymbol{\varepsilon}$ is the vector of residuals. The system matrix $\mathbf{A}$, the parameter vector $\mathbf{x}$ and the observation vector $\mathbf{I}$ are given by

$\mathbf{A}=\left(\begin{array}{ll}\kappa & t \\ 0 & 1 \\ 1 & 0\end{array}\right), \mathbf{x}=\left(\begin{array}{l}d T \\ d \kappa\end{array}\right), \mathbf{I}=\left(\begin{array}{c}l_{1}-t \kappa \\ l_{2}-t \\ l_{3}-t\end{array}\right)$

The elements $l_{1}, l_{2}$, and $l_{3}$, respectively, of the observation vector $\mathbf{I}$ are formed by the observables $T \Delta \rho, \Delta \rho$ and $T$. The parameter vector $\mathbf{x}$ consists of the unknown correc- 
tions $d T$ and $d \kappa$ to the a priori (initial) values of $T$ and $\Delta \rho$. The solution is found based on solving the system of normal equations $\hat{\mathbf{x}}=\mathbf{N}^{-1} \mathbf{A}^{\mathrm{T}} \mathbf{Q}^{-1} \mathbf{l}$; where $\mathbf{N}=\mathbf{A}^{\mathrm{T}} \mathbf{Q}^{-1} \mathbf{A}$ is the normal matrix, and $\mathbf{Q}$ denotes the variance-covariance matrix.

\section{ISOSTATIC GRAVITY ANOMALIES}

The study area comprising the Himalayas, Tibet and Central Siberia is bounded by the parallels 20 and 60 arcdeg northern latitudes and the meridians 60 and 120 arc-deg eastern longitudes. The topography/bathymetry over the study area including a description of the major geological regions is shown in Fig. 1.

The global geopotential model (GOCO02S) and the global topographic/bathymetric model (DTM2006.0) were used to compute the isostatic gravity anomalies with a spectral resolution complete to degree 180 of the spherical harmonics. This computation was realized on a $1 \times 1$ arc-deg geographical grid of surface points. The coefficients of the combined GRACE and GOCE satellite global geopotential model GOCO02S (Goiginger et al. 2011) were used to generate the gravity anomalies. The normal gravity component was computed according to the GRS-80 parameters (Moritz 1980).

The recent studies based on a regional accuracy assessment of global geopotential models have shown that the combined satellite-only GRACE/GOCE solutions pro- vide a substantial improvement of the Earth's gravity field at a medium-wavelength part of gravity spectra (within the frequency band approximately between 100 and 250) when compared to satellite-only GRACE models (cf. e.g., Goiginger et al. 2011). A significant improvement of gravity spectra at medium wavelengths by GOCE data was also demonstrated based on comparison with the combined satellite-terrestrial gravitational model EGM08 (Pavlis et al. 2012). Test results (not shown herein) revealed that the differences between the GOCO02S and EGM08 gravity field reach as much as $\pm 60 \mathrm{mGal}$ within our study area.

The refined Bouguer gravity anomalies were obtained after applying the Bouguer gravity reduction to the GOCO02S gravity anomalies. The Bouguer gravity reduction was computed using the coefficients of the global topographic/bathymetric model DTM2006.0 (Pavlis et al. 2007). The average density of the upper continental crust $2670 \mathrm{~kg} \mathrm{~m}^{-3}$ (cf. Hinze 2003) was adopted as the topographic and reference crustal density. For the adopted values of the reference crustal density $2670 \mathrm{~kg} \mathrm{~m}^{-3}$ and the mean seawater density $1027 \mathrm{~kg} \mathrm{~m}^{-3}$, the ocean density contrast equals $1643 \mathrm{~kg} \mathrm{~m}^{-3}$.

The regional map of the GOCO02S gravity anomalies and the refined Bouguer gravity anomalies, both computed with a spectral resolution complete to degree 180 of the spherical harmonics, are shown in Figs. 2 and 3. The GOCO02S gravity anomalies are between -185 and $193 \mathrm{mGal}$. The refined Bouguer gravity anomalies vary from -569 to

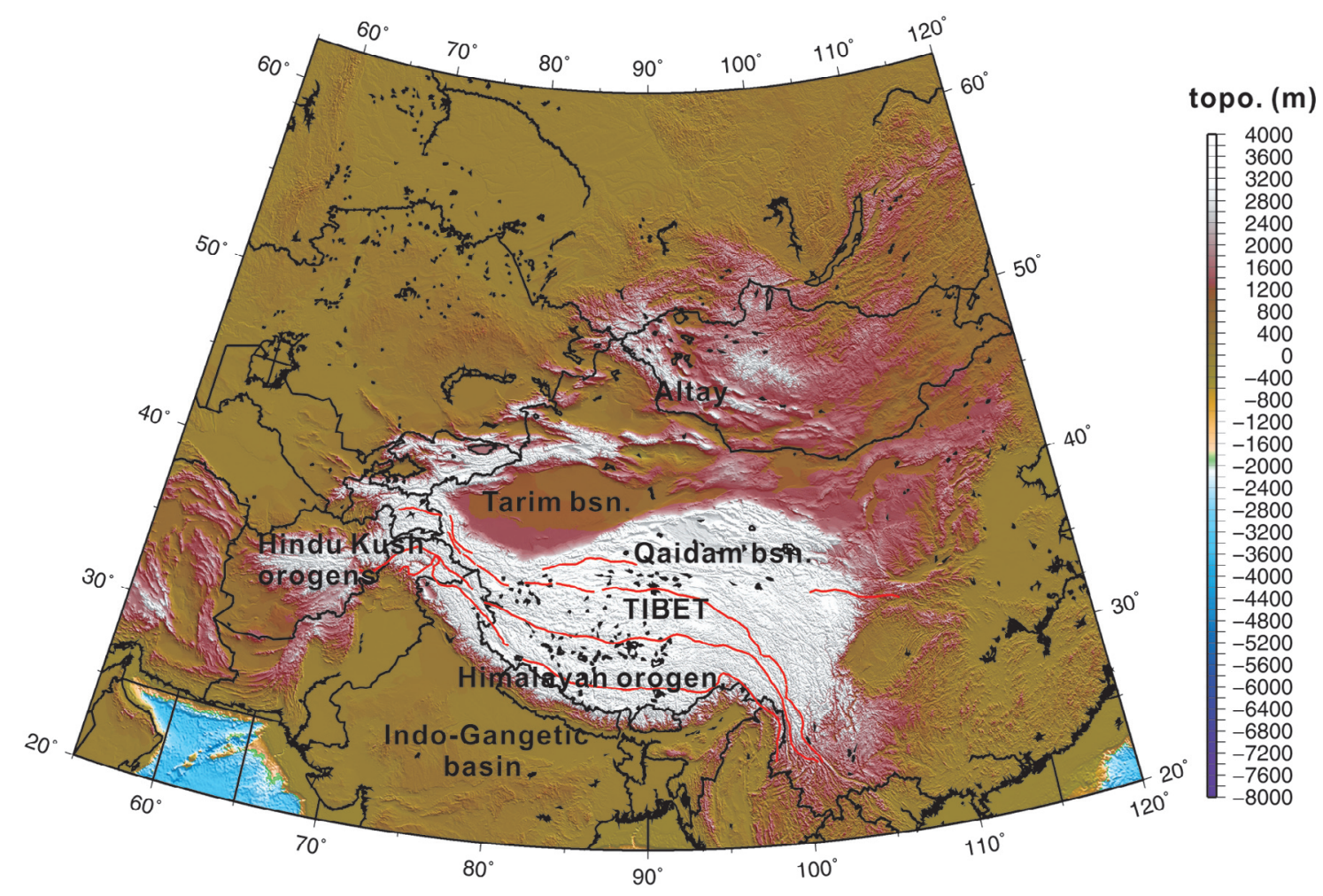

Fig. 1. Topography/bathymetry of the study area. 


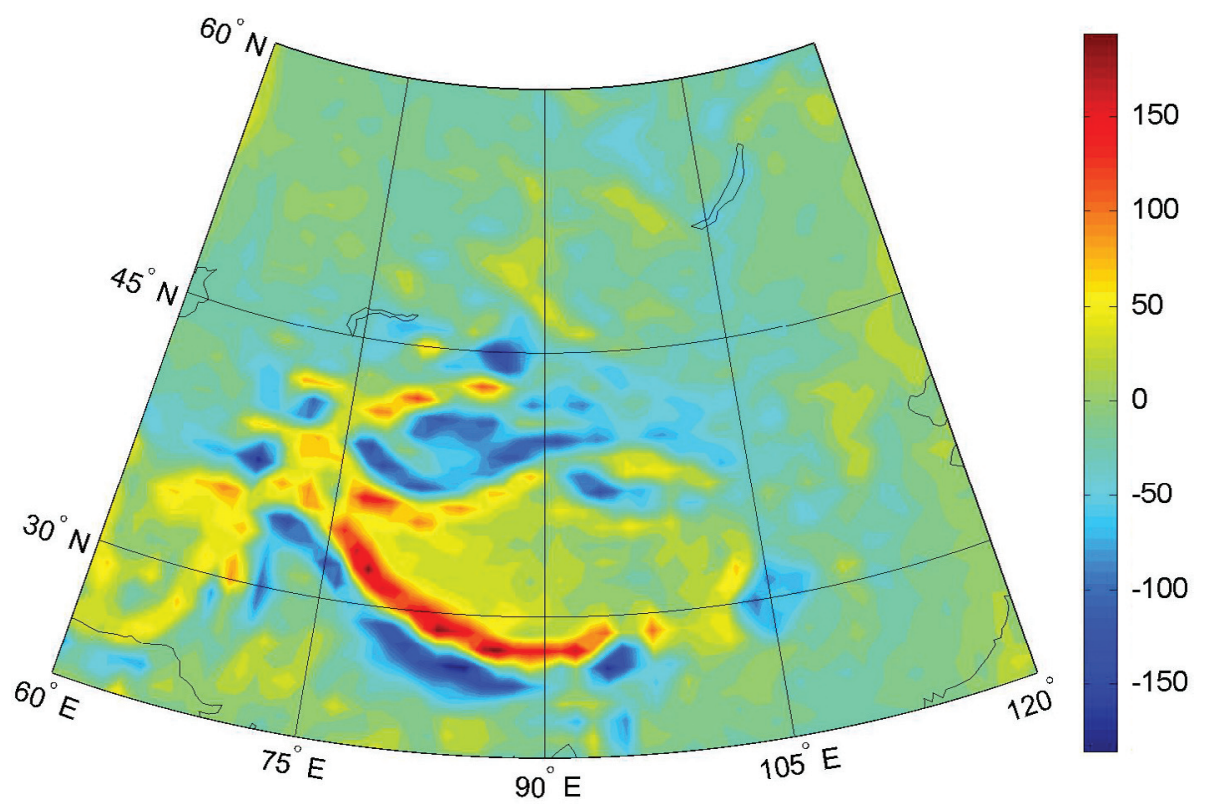

Fig. 2. GOCO02S gravity anomalies computed on a $1 \times 1$ arc-deg grid at the surface points with a spectral resolution complete to the spherical harmonic degree 180 . The units are in mGal.

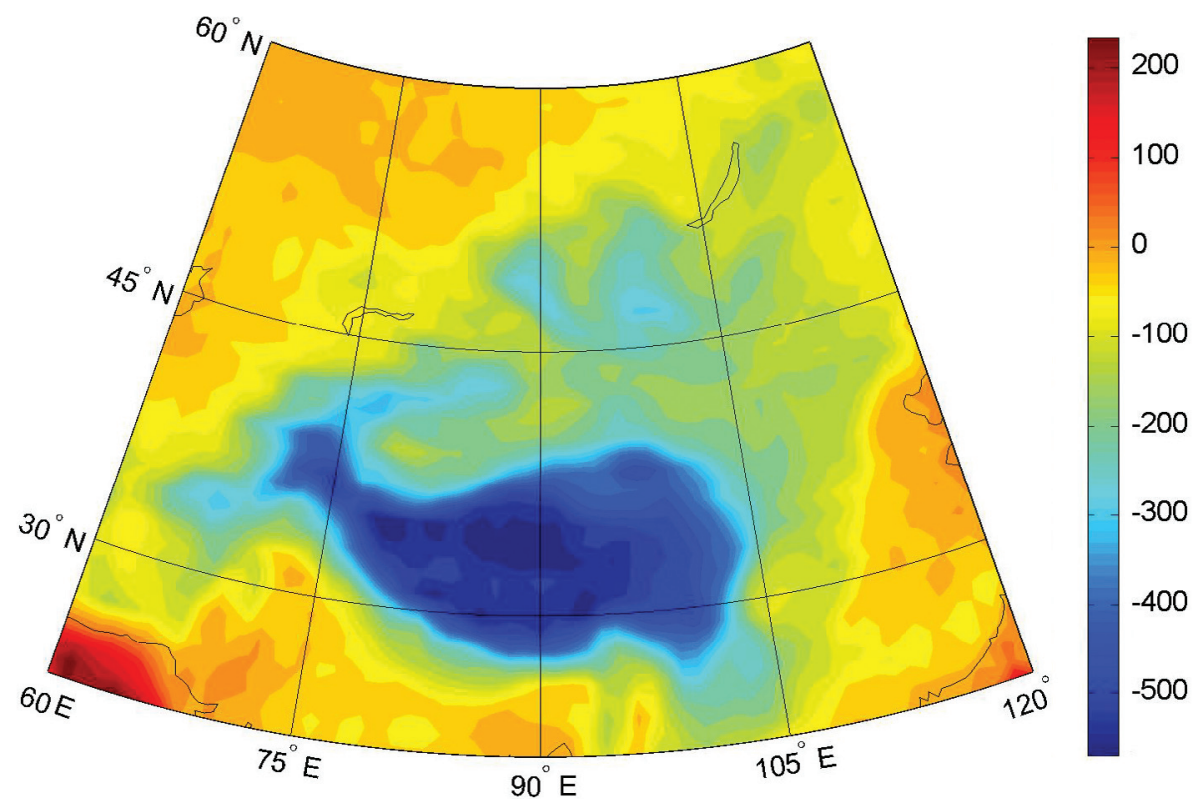

Fig. 3. Refined Bouguer gravity anomalies computed on a $1 \times 1$ arc-deg grid at the surface points with a spectral resolution complete to the spherical harmonic degree 180 . The units are in mGal.

$233 \mathrm{mGal}$. The orogenic belt corresponding to the convergence between the Indian and Eurasian continental tectonic plates is the most pronounced in the gravity field (see Fig. 2). Here we observe large horizontal spatial gravity anomaly variations with positive values in the Himalayas and corresponding negative values along the Indus-Gangetic basin. The mostly positive gravity anomalies are seen also over Tibet. Further north, the Altyn Tagh fault and the
Tarim and Qaidam basins are characterized mainly by the negative gravity anomalies. The gravity signal over Central Siberia is more likely associated with the rock structures of major geological provinces of shields, platforms and basins. Here the gravity anomalies have either small negative or positive values. Bouguer gravity reduction application substantially changed the gravity field over the mountains (see Fig. 3). The continental margins of the Indian plate are 
characterized by positive gravity anomaly values. These gravity anomalies become negative over continents with the minima below $-500 \mathrm{mGal}$ in the Himalayas and Tibet.

\section{MOHO PARAMETERS}

The isostatic gravity anomalies were used to estimate the Moho parameters over the study area. The system of (linearized) observation equations was solved by applying the least-squares adjustment using the elements method. The initial values of the Moho depths were taken from CRUST2.0 (Bassin et al. 2000). The Moho density contrast was determined relative to the adopted reference crustal density of $2670 \mathrm{~kg} \mathrm{~m}^{-3}$. The observation vector $\mathbf{l}$ in Eq. (6) was composed of three observation types; namely $l_{1}=T \Delta \rho$ [Eq. (1)], $l_{2}=\Delta \rho$ [Eq. (2)], and $l_{3}=T_{S}$ formed by the CRUST2.0 Moho depth values. The variance-covariance matrix $\mathbf{Q}$ in the least-squares estimation model reads (cf. Sjöberg and Bagherabndi 2011)

$\mathbf{Q}=\left(\begin{array}{ccc}\sigma_{1}^{2} & \sigma_{1}^{2} / t & 0 \\ \sigma_{1}^{2} / t & \sigma_{2}^{2} & 0 \\ 0 & 0 & \sigma_{3}^{2}\end{array}\right)$

where $\sigma_{1}$ and $\sigma_{3}$ are the standard errors of the parameters $T \Delta \rho$ and $T$, respectively, and $\sigma_{2}^{2}=\sigma_{1}^{2} / t^{2}+\sigma_{3}^{2}(T \Delta \rho)^{2} / t^{4}$. The standard error $\sigma_{1}$ of $T \Delta \rho$ was computed using the following expression

$\sigma_{1}^{2}=\sigma_{T \Delta \rho}^{2} \approx\left(\frac{\gamma_{0}}{4 \pi G}\right)^{2} \sum_{n, m} N_{n, m}^{2} \sigma_{n, m}^{2}$

where $\gamma_{0}$ is the GRS-80 normal gravity, $N_{n, m}=(2 n+1)(n-1) /$ $(n+1)$, and $\sigma_{n, m}^{2}$ are the error degree potential coefficients. The CRUST2.0 Moho depths data are not provided with the standard error model. Hence, we assumed the representative uncertainties (i.e., standard error $\sigma_{3}$ in the matrix $\mathbf{Q}$ ) of the Moho depth data of $\sim 20 \mathrm{~km}$. This corresponds to relative Moho uncertainties of $\sim 30 \%$ or more depending on the actual Moho depths. This value was chosen empirically based on a range of differences in the Moho depth estimated values under the Himalayas and Tibetan Plateau, as summarized in section 1. A realistic estimation of the Moho depth errors is obviously not simple. Čadek and Martinec (1991), for instance, estimated the uncertainties of the Moho depths in their global crust thickness model to be about $20 \%$ (5 km) for the oceanic crust and of $\sim 10 \%$ ( $3 \mathrm{~km}$ ) for the continental crust. The results of more recent seismic and gravity studies, however, revealed that these error estimates are too optimistic. Grad et al. (2009) demonstrated that the Moho uncertainties (estimated based on processing the seismic data) under Europe regionally exceed $10 \mathrm{~km}$ with the average er- ror of more than $4 \mathrm{~km}$. Much larger Moho uncertainties are to be expected over large parts of the world where seismic data are absent or insufficient (such as our study area).

The estimated Moho parameters on a $1 \times 1$ arc-deg grid within the study area are shown in Figs. 4 and 5. The Moho depths vary from 34 to $79 \mathrm{~km}$. The Moho density contrast (determined relative to the adopted reference crustal density of $2670 \mathrm{~kg} \mathrm{~m}^{-3}$ ) varies between 380 and $710 \mathrm{~kg} \mathrm{~m}^{-3}$.

\section{DISCUSSION}

The largest continental crustal thickness is confirmed under the Himalayas; the Moho depths there reach $79 \mathrm{~km}$. The locations of large crustal thickness further extend under the Tibetan plateau with typical Moho depths of $70-75 \mathrm{~km}$ and the maxima found in northern Tibet. In Central Tibet, more shallow Moho depths of $\sim 65 \mathrm{~km}$ correspond with the Bangong-Nujiang suture. These results agree with the findings of Braitenberg et al. (2000b), Kind et al. (2002), and others (see section 1). There are several different theories explaining a large crustal thickness beneath the Tibetan plateau. The collision of the Indian and Eurasian plates, which began in Paleogene and continues today (at a rate to about $5 \mathrm{~cm} \mathrm{yr}^{-1}$; cf. e.g., Bilham et al. 1997), have been forming the Himalayan and Tibetan orogenic belt. The geological structure of Tibet is characterized by several sub-plates that were successively accumulated into the Eurasian plate during Paleozoic and Mesozoic periods. The results of paleomagnetic analysis acquired that these sub-plates were moved from the southern hemisphere during the Paleozoic period northward as the intervening ocean subducted and subsequently accreted to the Eurasian plate. The resulting sutures are marked by distinctive geological formations and fault zones. For more information describing the geological structures and tectonic configuration we refer readers to studies, for instance, by Allègre et al. (1984) and Molnar (1986). This collision resulted in the subduction of a large part of the oceanic crust underneath the Tibetan plateau. Zeng et al. (2002) observed multiple crustal subduction features under the Himalayas and southern Tibet. Tilman et al. (2003) reported that the front of the Indian lithospheric mantle was detached below the Qiantang block, where the asthenosphere ascended and was exchanged with the lithosphere. The geophysical evidences also indicate that the subducted crust of the Indian plate detached from its upper part while the Indian lithospheric mantle is assimilating into the upper mantle (cf. Wu et al. 2004). Xu et al. (2004) reported that the Indian lithospheric slab is being subducted underneath the Tanggula Mountains. A large high-velocity anomalous zone was split into separate high-velocity anomalous bodies, which may be considered geophysical evidence for the abruption caused by the subduction of the Indian lithospheric mantle. The studies by Wittlinger et al. (2004) and Rai et al. (2006) suggest that the Indian plate may penetrate as far 


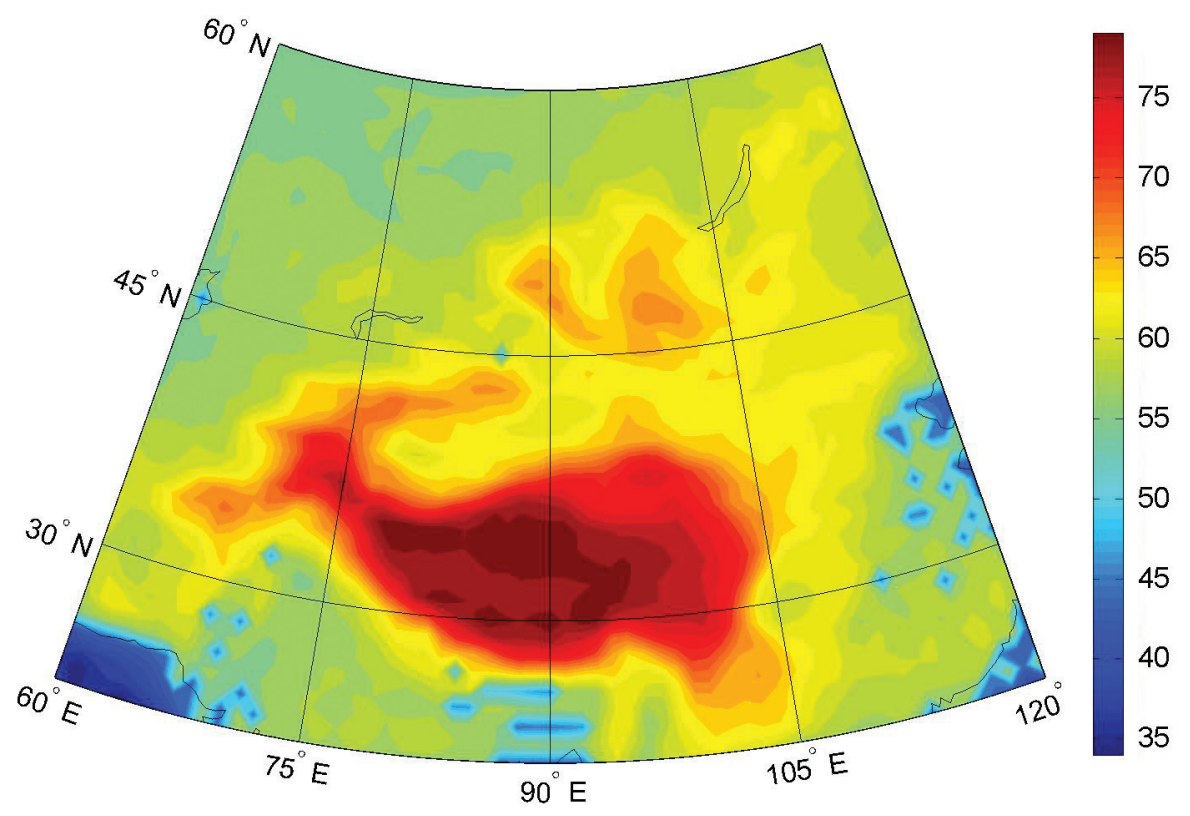

Fig. 4. Moho depths computed on a $1 \times 1$ arc-deg grid. The units are in $\mathrm{km}$.

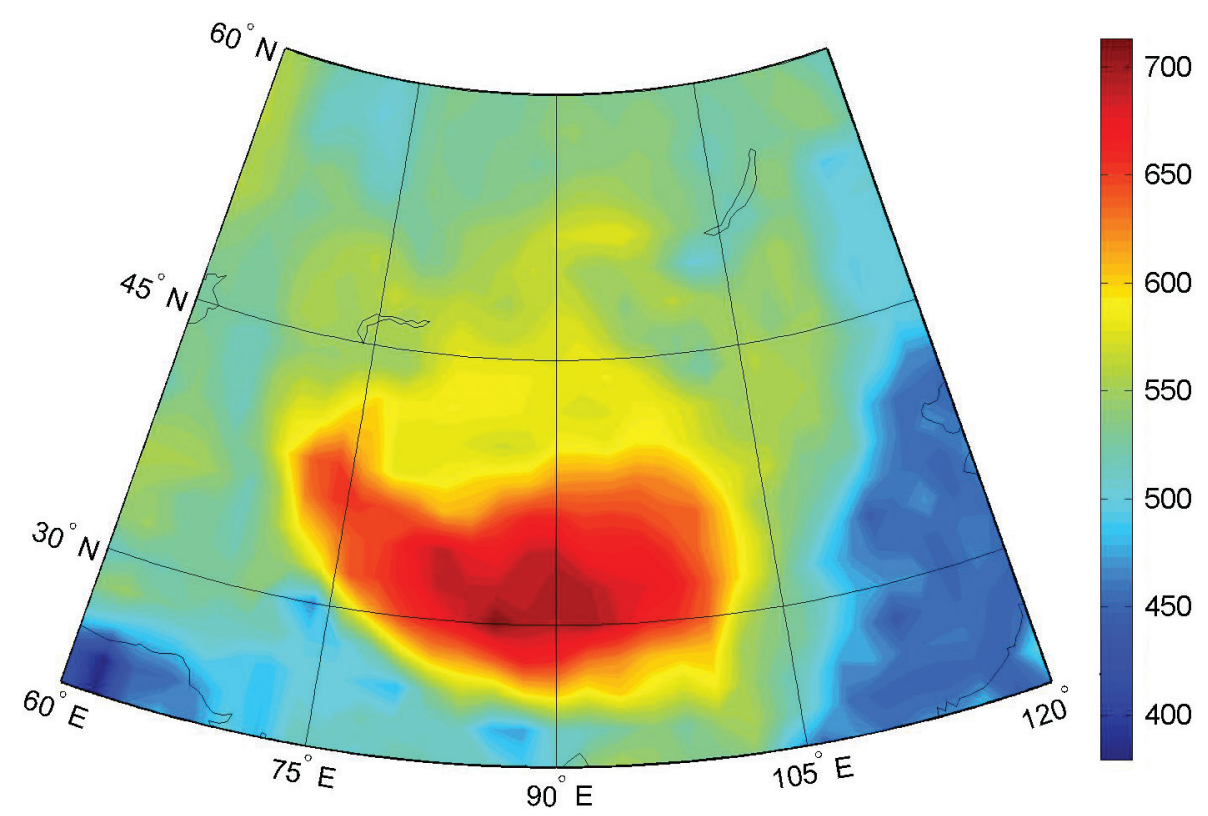

Fig. 5. Moho density contrast (defined relative to the adopted reference crustal density of $2670 \mathrm{~kg} \mathrm{~m}^{-3}$ ) computed on a $1 \times 1$ arc-deg grid. The units are in $\mathrm{kg} \mathrm{m}^{-3}$.

as the Bangong suture, and possibly as far north as the Altyn Tagh. Alternative theories facilitate the hypothesis of crustal shortening and consequent crust thickening attributed to the extrusion or escape tectonics mechanism (Molnar and Tapponnier 1975). According to these theories the motion of the Indian plate pressed the Indochina block, and a proposed mechanism is that a large part of the crustal shortening was accommodated by thrusting and folding of the sediments of the passive Indian margin together with the deformation of the Tibet crust (Dewey et al. 1989).

Large crustal thickness of $60-65 \mathrm{~km}$ was confirmed also beneath the Altay and Hindu Kush. These features are in the contrast to large basins to the south and southwest of the Himalayas as well as to the north of Tibet with a much thinner continental crust. The Moho depths beneath the Tarim and Qaidam basins were found to be below $\sim 60 \mathrm{~km}$. The 
similar Moho depths estimates under the Tarim basin were given, for instance, by Wittlinger et al. (2004). The IndoGangetic basin has a crustal thickness of $45-55 \mathrm{~km}$. According to our estimates the crustal thickness beneath Central Siberia is typically $50-60 \mathrm{~km}$ with some more detailed structures of deeper crustal roots. The crustal structure of Central Siberia consists of two distinctive tectonic regions, the Paleozoic west Siberian basin and the Precambrian Siberian Craton (which extends from the Ural orogen to the Lena river basin). Tectonic configuration indicates that the crustal evolution of these regions began approximately $4 \mathrm{Ga}$ ago. The Moho depths beneath Archean terranes were estimated to be $60-65 \mathrm{~km}$. The crustal thickness slightly decreases under Paleo-Mesoproterozoic terranes and Mesozoic and Cenozoic regions, where the Moho depths are typically less than $60 \mathrm{~km}$. The largest Moho depths of 61 $64 \mathrm{~km}$ were found at the southern part of the Siberian Craton. The Moho depths beneath the Paleozoic west Siberian basin are according to our estimates $\sim 53 \mathrm{~km}$. Some more detailed structures of the crustal thickness can be recognized along the Baikal rift zone which is a boundary between the Amur sub-plate and the Eurasian plate (Wei and Seno 1998). Here the Moho locally deepens to $\sim 62 \mathrm{~km}$.

We further compared our estimates (re-sampled to $2 \times$ 2 arc-deg grid) with the CRUST2.0 Moho depths. The differences between our and CRUST2.0 Moho depths are shown in Fig. 6. These differences within the study area vary between -9.0 and $18.3 \mathrm{~km}$ with the mean of $-3.4 \mathrm{~km}$ and the RMS of differences is $5.7 \mathrm{~km}$. As seen from this comparison, the largest absolute differences are found in Himalayas (differences are mostly $>10 \mathrm{~km}$ ). Our results more closely correspond with the CRUST2.0 Moho depths under Siberia (differences are mainly within $\pm 5 \mathrm{~km}$ ). The CRUST2.0 and our estimates of the crustal thickness beneath Central Siberia are, however, substantially larger than the Moho depths derived from seismic data, for instance, by Pavlenkova (1996), Zorin et al. (2002) and Pavlenkova and Pavlenkova (2006). They reported a typical thickness of the Siberian crust of $35-45 \mathrm{~km}$.

The largest values of the Moho density contrast (defined relative to the reference crustal density of $2670 \mathrm{~kg} \mathrm{~m}^{-3}$ ) are under the Himalayan and Tibetan orogens. Here the maxima exceed $550 \mathrm{~kg} \mathrm{~m}^{-3}$ and locally reach as much as $\sim 700 \mathrm{~kg} \mathrm{~m}^{-3}$. Since the Moho density contrast was determined with respect to the reference crustal density (of $2670 \mathrm{~kg} \mathrm{~m}^{-3}$ ), the density of the upper mantle underlying the crust can be calculated from these values. The estimated upper mantle density under Himalayas and Tibet is typically $3200-3400 \mathrm{~kg} \mathrm{~m}^{-3}$. The continental upper mantle density increases with depth. The largest values are thus under significant orogens with the largest crustal thickness. We further used these upper mantle density values to determine the Moho density contrast with respect to the CRUST2.0 lower crustal densities. These values should optimally represent the real Moho density contrast. The Moho density contrast under the continental crust in this case generally does not increases everywhere with depths. Its maxima are found beneath central Tibet; here the density contrast is $\sim 300 \mathrm{~kg} \mathrm{~m}^{-3}$. The Moho density contrast, however, substantially decreases to $150-250 \mathrm{~kg} \mathrm{~m}^{-3}$ under the deepest mountain roots of Himalayas and north Tibet. The Moho density contrast in Central Siberia is typically within $100-200 \mathrm{~kg} \mathrm{~m}^{-3}$.

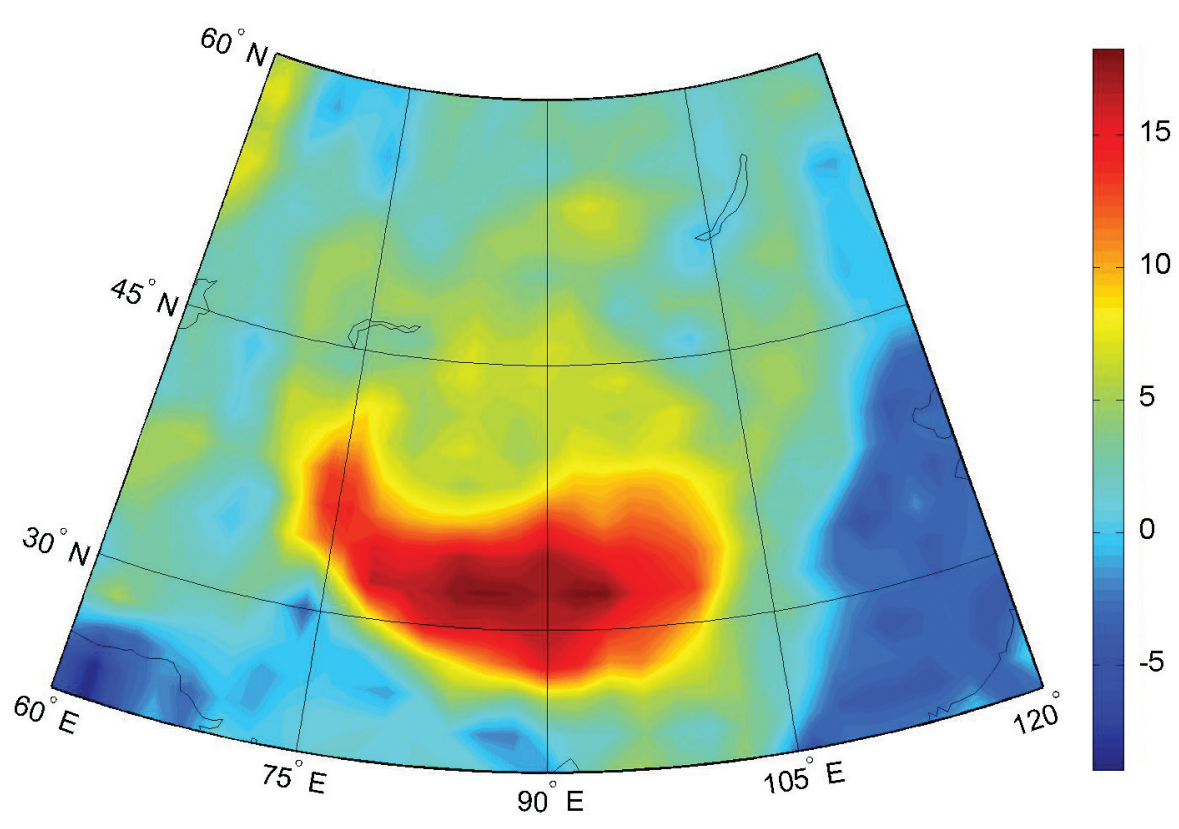

Fig. 6. Moho depth differences obtained from the combined approach and CRUST2.0. The units are in km. 


\section{CONCLUSIONS}

The convergent tectonic plate boundaries marked distinctively by the positive gravity anomalies along the orogens are coupled with the negative gravity anomalies along the sides of subducted crust. In the gravity map these features are seen along the continent-to-continent collision zone of the Indian and Eurasian tectonic plates (Himalayan orogen and the Indo-Gangetic basin). The large positive gravity anomalies over the Tibetan, Altay and Hindu Kush orogens are coupled by the negative gravity disturbances over the Tarim and Qaidam basins.

Bouguer gravity reduction application substantially changed the gravity signal over Himalayas and Tibet with the gravity anomaly minima below $-500 \mathrm{mGal}$. The resulting refined Bouguer gravity anomalies are significantly correlated with the Moho geometry. The largest crustal thickness was confirmed under the Himalayan and Tibetan orogens with the Moho depths exceeding $65 \mathrm{~km}$ and reaching the maxima of $\sim 79 \mathrm{~km}$. This maximum Moho depth differs $\sim 10 \%$ from the corresponding maximum of $72 \mathrm{~km}$ estimated based on using EGM08 and DTM2006.0 by Bagherbandi (2012). The contrast between the crustal thickness beneath orogens and basins is clearly distinguished by more shallow Moho depths $(<60 \mathrm{~km})$ under Indo-Gangetic, Tarim and Qaidam basins. Our estimates of the Siberian crustal thickness are similar to CRUST2.0 Moho depths, but both are significantly larger than that obtained from regional seismic studies. This misfit between the regional and global seismic models might be explained by a low quality of CRUST2.0 in this part of the world. Consequently, our gravimetric solution, complied using the CRUST2.0 Moho depths in forming the observation equations, agree better with CRUST2.0 than with regional seismic results.

The Moho density contrast typically increases with depth. However, this trend is not representative everywhere under the continental crust. Our results revealed that the density contrast of the deepest crustal structures is often much less pronounced compared to the upper mantle. When taking into consideration the Moho density contrast computed with respect to the CRUST2.0 lower crustal densities the maxima of $\sim 300 \mathrm{~kg} \mathrm{~m}^{-3}$ are found under Central Tibet. On the other hand, the Moho density contrast under the deepest crustal structures of the Himalayas and northern Tibet is only $150-250 \mathrm{~kg} \mathrm{~m}^{-3}$. The Moho density contrast of 100 $200 \mathrm{~kg} \mathrm{~m}^{-3}$ was estimated over most of Central Siberia.

Acknowledgements The Swedish National Space Board (SNSB) is cordially acknowledged for financial support of the project No. 76/10:1.

\section{REFERENCES}

Allègre, C. J., V. Courtillot, P. Tapponnier, A. Hirn, M. Mattauer, C. Coulon, J. J. Jaeger, J. Achache, U. Schär- er, J. Marcoux, J. P. Burg, J. Girardeau, R. Armijo, C. Gariépy, C. Göpel, T. Li, X. Xiao, C. Chang, G. Li, B. Lin, J. Teng, N. Wang, G. Chen, T. Han, X. Wang, W. Den, H. Sheng, Y. Cao, J. Zhou, H. Qiu, P. Bao, S. Wang, B. Wang, Y. Zhou, and R. Xu, 1984: Structure and evolution of the Himalaya-Tibet orogenic belt. $\mathrm{Na}$ ture, 307, 17-22, doi: 10.1038/307017a0. [Link]

Bagherbandi,M.,2012: A comparison of three gravity inversion methods for crustal thickness modelling in Tibet plateau. J. Asian Earth Sci., 43, 89-97, doi: 10.1016/j. jseaes.2011.08.013. [Link]

Bassin, C., G. Laske, and G. Masters, 2000: The current limits of resolution for surface wave tomography in North America. Eos, Trans., AGU, 81, F897.

Bilham, R., K. Larson, and J. Freymueller, 1997: GPS measurements of present-day convergence across the Nepal Himalaya. Nature, 386, 61-64, doi: 10.1038/386061a0. [Link]

Braitenberg, C., M.Zadro, J. Fang, Y. Wang, and H. T. Hsu, 2000a: Gravity inversion in Qinghai-Tibet plateau. Phys. Chem. Earth, 25, 381-386, doi: 10.1016/S14641895(00)00060-0. [Link]

Braitenberg, C., M.Zadro, J. Fang, Y. Wang, and H. T. Hsu, 2000b: The gravity and isostatic Moho undulations in Qinghai-Tibet plateau. J. Geodyn., 30, 489-505, doi: 10.1016/S0264-3707(00)00004-1. [Link]

Čadek, O. and Z. Martinec, 1991: Spherical harmonic expansion of the earth's crustal thickness up to degree and order 30. Stud. Geophys. Geod., 35, 151-165.

Caporali, A., 1995: Gravity anomalies and the flexure of the lithosphere in the Karakoram, Pakistan. J. Geophys. Res., 100, 15075-15085, doi: 10.1029/95JB00613. [Link]

Caporali, A., 1998: Gravimetric constraints on the rheology of the Indian and Tarim plates in the Karakoram continent - Continent collision zone. J. Asian Earth Sci., 16, 313-321, doi: 10.1016/S0743-9547(98)00005-1. [Link]

Caporali, A., 2000: Buckling of the lithosphere in western Himalaya: Constraints from gravity and topography data. J. Geophys. Res., 105, 3103-3113, doi: 10.1029/ 1999JB900389. [Link]

Dewey, J. F., S. Cande, and W. C. Pitman, 1989: Tectonic evolution of the Indian/Eurasia collision zone. Eclog. geol. Helv., 82, 717-734.

Gao, R., Z. Lu, Q. Li, Y. Guan, J. Zhang, R. He, and L. Huang, 2005: Geophysical survey and geodynamic study of crust and upper mantle in the Qinghai-Tibet Plateau. Episode, 28, 263-273.

Goiginger, H., D. Rieser, T. Mayer-Guerr, R. Pail, W.-D. Schuh, A. Jäggi, and A. Maier, 2011: GOCO, Consortium: The combined satellite-only global gravity field model GOCO02S. European Geosciences Union General Assembly 2011, Wien, April 4, 2011.

Grad, M., T. Tiira, and ESC Working Group, 2009: The 
Moho depth map of the European Plate. Geophys. J. Int., 176, 279-292, doi: 10.1111/j.1365-246X.2008.03 919.x. [Link]

Hinze, W. J., 2003: Bouguer reduction density, why 2.67 ? Geophysics, 68, 1559-1560, doi: 10.1190/1.1620629. [Link]

Hirn, A., J.-C. Lepine, G. Jobert, M. Sapin, G. Wittlinger, Z. X. Xu, E. Y. Gao, X. J. Wang, J. W. Teng, S. B. Xiong, M. R. Pandey, and J. M. Tater, 1984: Crustal structure and variability of the Himalayan border of Tibet. $\mathrm{Na}$ ture, 307, 23-25, doi: 10.1038/307023a0. [Link]

Kind, R., J. Ni, W. Zhao, J. Wu, X. Yuan, L. Zhao, E. Sandvol, C. Reese, J. Nabelek, and T. Hearn, 1996: Evidence from earthquake data for a partially molten crustal layer in Southern Tibet. Science, 274, 16921694, doi: 10.1126/science.274.5293.1692. [Link]

Kind, R., X. Yuan, J. Saul, D. Nelson, S. V. Sobolev, J. Mechie, W. Zhao, G. Kosarev, J. Ni, U. Achauer, and M. Jiang, 2002: Seismic images of crust and upper mantle beneath Tibet: Evidence for eurasian plate subduction. Science, 298, 1219-1221, doi: 10.1126/science.1078115. [Link]

Lyon-Caen, H. and P. Molnar, 1983: Constraints on the structure of the Himalaya from an analysis of gravity anomalies and a flexural model of the lithosphere. $J$. Geophys. Res., 88, 8171-8191, doi: 10.1029/JB088iB 10p08171. [Link]

Lyon-Caen, H. and P. Molnar, 1984: Gravity anomalies and the structure of western Tibet and the southern Tarim basin. Geophys. Res. Lett., 11, 1251-1254, doi: 10.10 29/GL011i012p01251. [Link]

Molnar, P., 1986: The geologic history and structure of the Himalaya. Am. Scientist, 74, 144-154.

Molnar, P. and P. Tapponnier, 1975: Cenozoic tectonics of Asia: Effects of a continental collision. Science, 189, 419-426, doi: 10.1126/science.189.4201.419. [Link]

Moritz, H., 1980: Advanced Physical Geodesy, Wichmann, Karlsruhe, 500 pp.

Nelson, K. D., W.Zhao, L. D. Brown, J. Kuo, J. Che, X. Liu, S. L. Klemperer, Y. Makovsky, R. Meissner, J. Mechie, R. Kind, F. Wenzel, J. Ni, J. Nabelek, L. Chen, H. Tan, W. Wei, A. G. Jones, J. Booker, M. Unsworth, W. S. F. Kidd, M. Hauck, D. Alsdorf, A. Ross, M. Cogan, C. Wu, E. Sandvol, and M. Edwards, 1996: Partially molten middle crust beneath southern Tibet: Synthesis of Project INDEPTH results. Science, 274, 1684-1688, doi: 10.1126/science.274.5293.1684. [Link]

Pavlenkova, N. I., 1996: Crust and upper mantle structure in Northern Eurasia from seismic data. In: Dmowska, R. and B. Saltzman (Eds.), Advances in Geophysics, vol. 37, 1-133, doi: 10.1016/S0065-2687(08)60269-1. [Link]

Pavlenkova, G. A. and N. I. Pavlenkova, 2006: Upper mantle structure of the Northern Eurasia from peaceful nu- clear explosion data. Tectonophysics, 416, 33-52, doi: 10.1016/j.tecto.2005.11.010. [Link]

Pavlis, N. K., J. K. Factor, and S. A. Holmes, 2007: Terrainrelated gravimetric quantities computed for the next EGM. Presented at the $1^{\text {st }}$ International symposium of the International gravity service 2006, August 28 September 1, Istanbul, Turkey.

Pavlis, N. K., S. A. Holmes, S. C. Kenyon, and J. K. Factor, 2012: The development and evaluation of the Earth Gravitational Model 2008 (EGM2008). J. Geophys. Res., 117, B04406, doi: 10.1029/2011JB008916. [Link]

Rai, S. S., K. Priestley, V. K. Gaur, S. Mitra, M. P. Singh, and M. Searle, 2006: Configuration of the Indian Moho beneath the NW Himalaya and Ladakh. Geophys. Res. Lett., 33, L15308, doi: 10.1029/2006GL026076. [Link]

Schulte-Pelkum, V., G. Monsalve, A. Sheehan, M. R. Pandey, S. Sapkota, R. Bilham, and F. Wu, 2005: Imaging the Indian subcontinent beneath the Himalaya. Nature, 435, 1222-1225, doi: 10.1038/nature03678. [Link]

Sjöberg, L. E., 2009: Solving Vening Meinesz-Moritz inverse problem in isostasy. Geophys. J. Int., 179, 15271536, doi: 10.1111/j.1365-246X.2009.04397.x. [Link]

Sjöberg, L. E. and M. Bagherbandi, 2011: A method of estimating the Moho density contrast with a tentative application of EGM08 and CRUST2.0. Acta Geophys., 59, 502-525, doi: 10.2478/s11600-011-0004-6. [Link]

Teng, J. W., Z. X. Yin, Xu, X. T. Wnag, and D. Y. Lu, 1983: Structure of the crust and upper mantle pattern and velocity distributional characteristics in the Northern Himalayan mountain region. Acta Geophys. Sin., 26, 525-540.

Tilmann, F., J. Ni, and INDEPTH III Seismic Team, 2003: Seismic imaging of the downwelling Indian lithosphere beneath central Tibet. Science, 300, 1424-1427, doi: 10.1126/science.1082777. [Link]

Watts, A. B., 2001: Isostasy and Flexure of the Lithosphere, Cambridge University Press, Cambridge, 458 pp.

Wei, D. and T. Seno, 1998: Determination of the Amurian plate motion. In: Flower, M. F. J., S. L. Chung, C. H. Lo, and T. Y. Lee (Eds.), Mantle Dynamics and Plate Interactions in East Asia, Geodynamics Series, vol. 27, AGU, Washington DC, 419 pp, doi: 10.1029/GD027. [Link]

Wittlinger, G., J. Vergne, P. Tapponnier, V. Farra, G. Poupinet, M. Jiang, H. Su, G. Herquel, and A. Paul, 2004: Teleseismic imaging of subducting lithosphere and Moho offsets beneath western Tibet. Earth Planet. Sci. Lett., 221, 117-130, doi: 10.1016/S0012-821 $\mathrm{X}(03) 00723-4$. [Link]

Wu, G., X. Xiao, and T. Li, 1991: Yadong to Golmud transect: Qinghai-Tibet plateau, China. In: Gongjian, W., X. Xuchang, and L. Tingdong (Eds.), Global Geo- 
science Transect, vol. 3, AGU, Washington DC, doi: 10.1029/GT003. [Link]

Wu, Q. J., R. S. Zeng, and W. J. Zhao, 2004: Dipping structure of upper mantle and continent-continent collision in Himalyas-Tibet Plateau. Sci. China, Ser. D, 34, 919925.

Wu, X. Z., C. L. Wu, J. Lu, and J. Wu, 1995: Research on the fine crustal structure of the northern Qilian-Nexi Corridor by deep seismic reflection. Chinese J. Geophys., 38, 29-35.

Xu, Z. Q., M. Jiang, J. S. Yang, G. Q. Xue, H. P. Su, H. B. Li, J. W. Cui, C. L. Wu, and F. H. Liang, 2004: Mantle structure of Qinghai-Tibet plateau: Mantle plume, mantle shear zone and delamination of lithospheric slab. Earth Sci. Front., 11, 329-343.

Zeng, R. S., Z. F. Ding, and Q. J. Wu, 1994: A review of the lithospheric structure in Tibetan plateau and constraints for dynamics. Acta Geophys. Sin., 37, 99-116.

Zeng, R. S., J. W. Teng, Y. K. Li, S. Klemperer, and L.
Q. Yang, 2002: Crustal velocity structure and eastward escaping of crustal material in the southern Tibet. Sci. China, 32, 793-798.

Zhang, Z. J., Y. K. Li, G. J. Wang, J. W. Teng, S. Klemperer, J. W. Li, J. Y. Gan, and Y. Chen, 2001: E-W Crustal structure under the northern Tibet revealed by wide-angle seismic profiles. Sci.China Ser.D, 31, 881888.

Zhao, W., K. D. Nelson, J. Che, J. Quo, D. Lu, C. Wu, and X. Liu, 1993: Deep seismic reflection evidence for continental underthrusting beneath southern Tibet. $\mathrm{Na}$ ture, 366, 557-559, doi: 10.1038/366557a0. [Link]

Zorin, Y. A., V. V. Mordvinova, E. K. Turutanov, B. G. Belichenko, A. A. Artemyev, G. L. Kosarev, and S. S. Gao, 2002: Low seismic velocity layers in the Earth's crust beneath Eastern Siberia (Russia) and Central Mongolia: receiver function data and their possible geological implication. Tectonophysics, 359, 307-327, doi: 10.1016/S0040-1951(02)00531-0. [Link] 